\title{
Acne Keloid
}

National Cancer Institute

\section{Source}

National Cancer Institute. Acne Keloid. NCI Thesaurus. Code C34346.

A chronic eruption of fibrous papules that develop and fuse to form a thick sclerotic, hypertrophic band at a site of deep folliculitis, usually along the posterior hairline of the scalp. It is most commonly seen in men of African descent. 